\title{
Seismic-induced accelerations detected by two parallel gravity meters in continuous recording with a high sampling rate at Etna volcano
}

\author{
Filippo Greco $\left({ }^{1}\right)$, Cosmo Carmisciano $\left({ }^{2}\right)$, Ciro Del Negro $\left({ }^{1}\right)$, Ivo Loretti $\left({ }^{3}\right)$, \\ Antonino Sicali $\left({ }^{1}\right)$ and Paolo Stefanelli $\left({ }^{2}\right)$ \\ (') Istituto Nazionale di Geofisica e Vulcanologia, Sezione di Catania, Italy \\ $\left.{ }^{(}{ }^{2}\right)$ Istituto Nazionale di Geofisica e Vulcanologia, Sede di Portovenere, Fezzano (SP), Italy \\ $\left(^{3}\right)$ ENI SpA AESI Dept. E\&P Division, San Donato Milanese (MI), Italy
}

\begin{abstract}
We analyse a microgravity data set acquired from two spring LaCoste \& Romberg gravity meters operated in parallel at the same site on Etna volcano (Italy) for about two months (August-September 2005). The high sampling rate acquisition $(2 \mathrm{~Hz}$ ) allowed the correlation of short-lasting gravity fluctuations with seismic events. After characterizing the oscillation behavior of the meters, through the study of spectral content and the background noise level of both sequences, we recognized fluctuations in the gravity data, spanning a range of periods from $1 \mathrm{~s}$ to about $30 \mathrm{~s}$ dominated by components with a period of about $15 \div 25 \mathrm{~s}$, during time intervals encompassing both local seismic events and large worldwide earthquakes. The data analyses demonstrate that observed earthquake-induced gravity fluctuations have some differences due to diverse spectral content of the earthquakes. When local seismic events which present high frequency content excite the meters, the correlation between the two gravity signals is poor (factor $<0.3$ ). Vice versa, when large worldwide earthquakes occur and low frequency seismic waves dominate the ensuing seismic wavefield, the resonance frequencies of the meters are excited and they react according to more common features. In the latter case, the signals from the two instruments are strongly correlated to each other (up to 0.9 ). In this paper the behaviors of spring gravimeters in the frequency range of the disturbances produced by local and large worldwide earthquakes are presented and discussed.
\end{abstract}

Key words gravimeters - earthquakes - seismic-induced effects - gravity fluctuations - resonance

\section{Introduction}

Temporal gravity changes in volcanic areas are related to several geophysical phenomena

Mailing address: Dr. Filippo Greco, Istituto Nazionale di Geofisica e Vulcanologia, Sezione di Catania, Piazza Roma 2, 95123 Catania, Italy; e-mail: greco@ct.ingv.it (sub-surface mass-redistributions and/or surface elevation changes, seismicity, etc.) and their amplitude, wavelength and duration depend on several parameters such as the size, depth and rates of evolution of the sources. The expected gravity changes due to volcanic sources range in amplitude between a few $\mu \mathrm{Gal}$ and several hundred $\mu \mathrm{Gal}\left(1 \mu \mathrm{Gal}=10^{-8} \mathrm{~ms}^{-2}\right)$ with a spectrum varying from 1 second to more than 1 year (Hinderer and Crossley, 2000). Microgravity observations at Mt. Etna have been routinely performed as both discrete (since 1986) and continuous (since 1998) measurements. To date, long-lasting gravity data-sets 


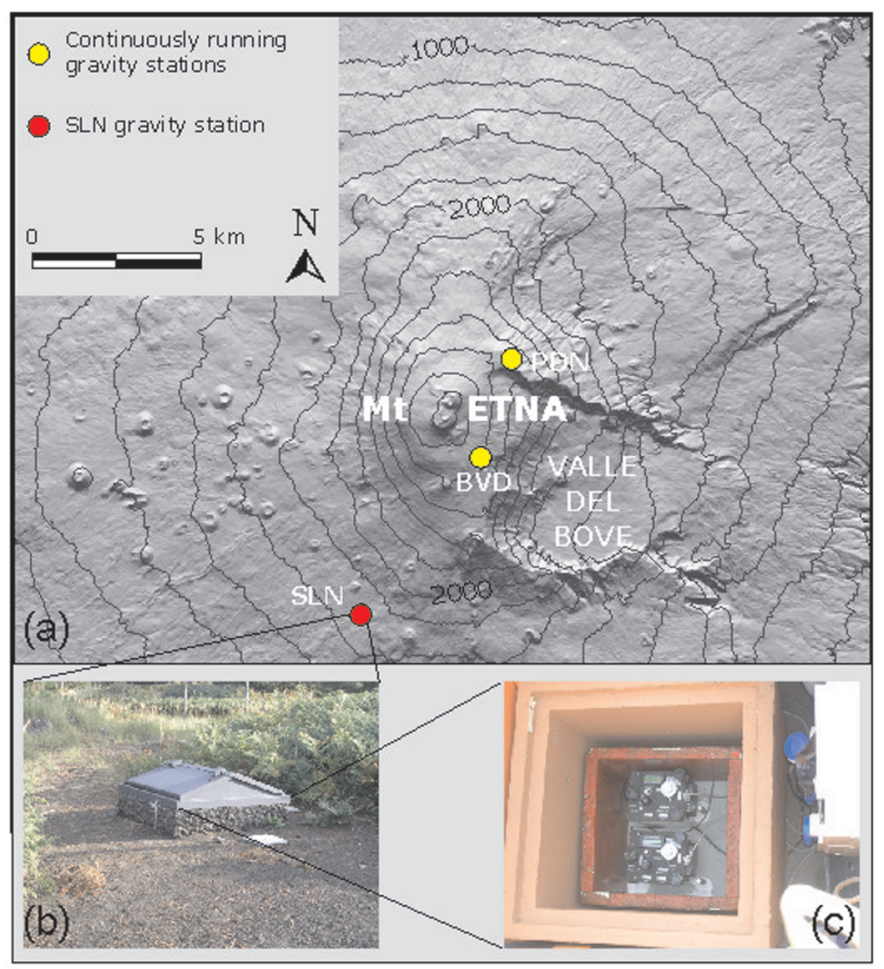

Fig. 1a-c. Schematic map of Mt Etna showing (a) the continuously recording gravity stations (PDN, BVD and SLN), b) the semi-underground box specifically built at SLN to accommodate continuously recording gravimeters and c) the position of two LaCoste \& Romberg gravimeters installed side-by-side within a thermally insulated polystyrene container inside the semi-underground box.

have been acquired and important gravity variations have been associated with the ensuing volcanic activity (Budetta et al., 1999; Branca et al., 2003; Carbone et al., 2003, 2006; Carbone and Greco, 2007).

In order to define the real potential for continuous gravity studies as an effective volcano monitoring tool, during the summer of 2005 we collected gravity data at a high sampling rate (2 $\mathrm{Hz}$; higher than that normally used for gravity recordings; $1 \mathrm{~min}$ ) at Etna volcano (Italy) using two gravimeters installed side-by-side (fig. 1).

It is worth stressing that the sampling rate used enlarges the observed spectral window from $1 \mathrm{~Hz}$ (Nyquist frequency in this experiment) to $0.008 \mathrm{~Hz}$ (Nyquist frequency in nor- mal gravity recordings). Consequently, the gravity information contents in this spectral window are scarcely documented in the literature since the previous continuous gravity recordings on active volcanoes were made at unsuitable sampling rates to permit their assessment.

Since the aim of this paper is to investigate the effect of local and large earthquakes on spring gravity meters, we will focus on the spectrum band of the gravity sequences ranging between a few hours and a few seconds.

This spectrum band is also particularly interesting because: i) it is contiguous to the spectrum band used for seismic studies (about 10$50,000 \mathrm{mHz}$ ) and thus allows phenomena with 
high rates of evolution to be monitored; ii) it is little perturbed by a) instrumental drift which is roughly linear within time intervals of the order of hours, b) tidal effects whose main components have periods clustered around 12 and 24 $h, c)$ pressure changes whose more energetic components occur over intervals of a few hours, d) temperature, whose effects, on continuously recording spring gravimeters are over periods longer than $24 \mathrm{~h}$ (Torge, 1989).

Analysis of this couple of 2-month-long gravity sequences evidenced some gravity fluctuations lasting from a few minutes to a few hours, with amplitudes ranging between a few $\mu \mathrm{Gal}$ and about $2000 \mu \mathrm{Gal}$.

This study demonstrates that these events appear only when either local earthquakes or large worldwide earthquakes dominate the ensuing seismic wavefield. At Mt. Etna, earthquakes mainly occur in the form of swarms. According to magnitude, this seismicity is composed of micro or small earthquakes, and seldom exceeds magnitude 4 (Ferrucci and Patanè, 1993). Also, the frequency range of a local earthquake ranging from 5 to $25 \mathrm{~Hz}$ (Patanè $e t$ al., 2004). Vice versa, the periods of the main spectral peaks during a teleseism (earthquake recorded by a seismograph at a distance over $1000 \mathrm{~km}$ from the epicenter; Richter, 1958), recorded by a long-period seismometer, ranging between $15 \div 20$ s.

Although in the considered period about 90 local earthquakes of magnitude $M_{d}$ ranging between 0.2 and 3.5 (INGV-CT; http://www.ct.ingv.it/GridTerremoti.htm/) and about 4500 worldwide earthquakes of magnitude ranging between 1.5 and 7.5 (USGS; http://earthquake.usgs.gov/ recenteqsww/Quakes/quakes_all.html/) were recorded, seismic-induced gravity fluctuations were observed only when the minimum thresholds of magnitude of about 2 and about 4 for local and for large worldwide earthquakes, respectively, were exceeded.

\section{Gravity data}

During the summer of 2005, with the aim of improving the understanding of cause-effect relationships that tie gravity variations to differ- ent sources, two LaCoste \& Romberg (LCR) G meters were utilized (G-594 and G-1190), each equipped with an Aliod 100 electronic feedback system (range and resolution are $100 \mathrm{mGal}$ and $0.01 \mathrm{mGal}$, respectively). Besides gravity, ground tilt along two perpendicular directions (cross and long) and the inner temperatures of the gravimeters were acquired. The acquisition system was managed by a high-integrated sin-

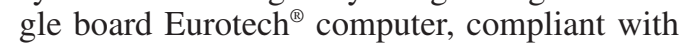
the PC/104 standard, equipped with a PCMCIA slot where a $32 \mathrm{Mb}$ ATA-IDE flash memory card was employed. It stores the operating system, the user programs and the data files. The system time base is always kept to UTC by a GPS clock. During the entire period of the experiment, data were periodically dumped by linking a laptop PC with a flash memory card to the acquisition system.

The continuous recording gravity station was installed on Etna's southern flank, at the Osservatorio Astrofisico in Serra La Nave (latitude $=37^{\circ} 41.4$; longitude $=14^{\circ} 58.7$; height $=$ $1700 \mathrm{~m}$ a.s.1.), $c a .10 \mathrm{~km}$ south of the active craters (fig. 1). The location was chosen for logistic reasons (easy access, availability of electrical energy, relatively low volcanic noise). The instruments were installed inside a semiunderground box specifically built to accommodate continuously recording gravimeters (fig. 1). Some shortcomings, of the order of a few hours, due to temporary failures of the powering system of Serra La Nave (SLN) station affected the data sequences (the longest of these occurred between 3 and 9 September and between 12 and 13 September). However, in spite of these gaps, the sequences acquired simultaneously on Etna are useful and yield a great deal of information (over periods ranging from a few seconds to a few hours).

During the 2-month long recording period four significant gravity fluctuations, lasting about $120 \mathrm{~s}$ each, spanning a wide range of periods (from $1 \mathrm{~s}$ to about $30 \mathrm{~s}$ ), and with amplitude ranging between about 100 and about $2000 \mu \mathrm{Gal}$ peak-to-peak) were observed on 14 August, 2005 (between 21:09 and 22:06 GMT; fig. 2), during a seismic swarm of 18 earthquakes (magnitude $M_{d}$ ranging from 1.7 to 3.5 and hypocentral depth ranging from 1 to $3 \mathrm{~km}$ ) with the epicentre on the 

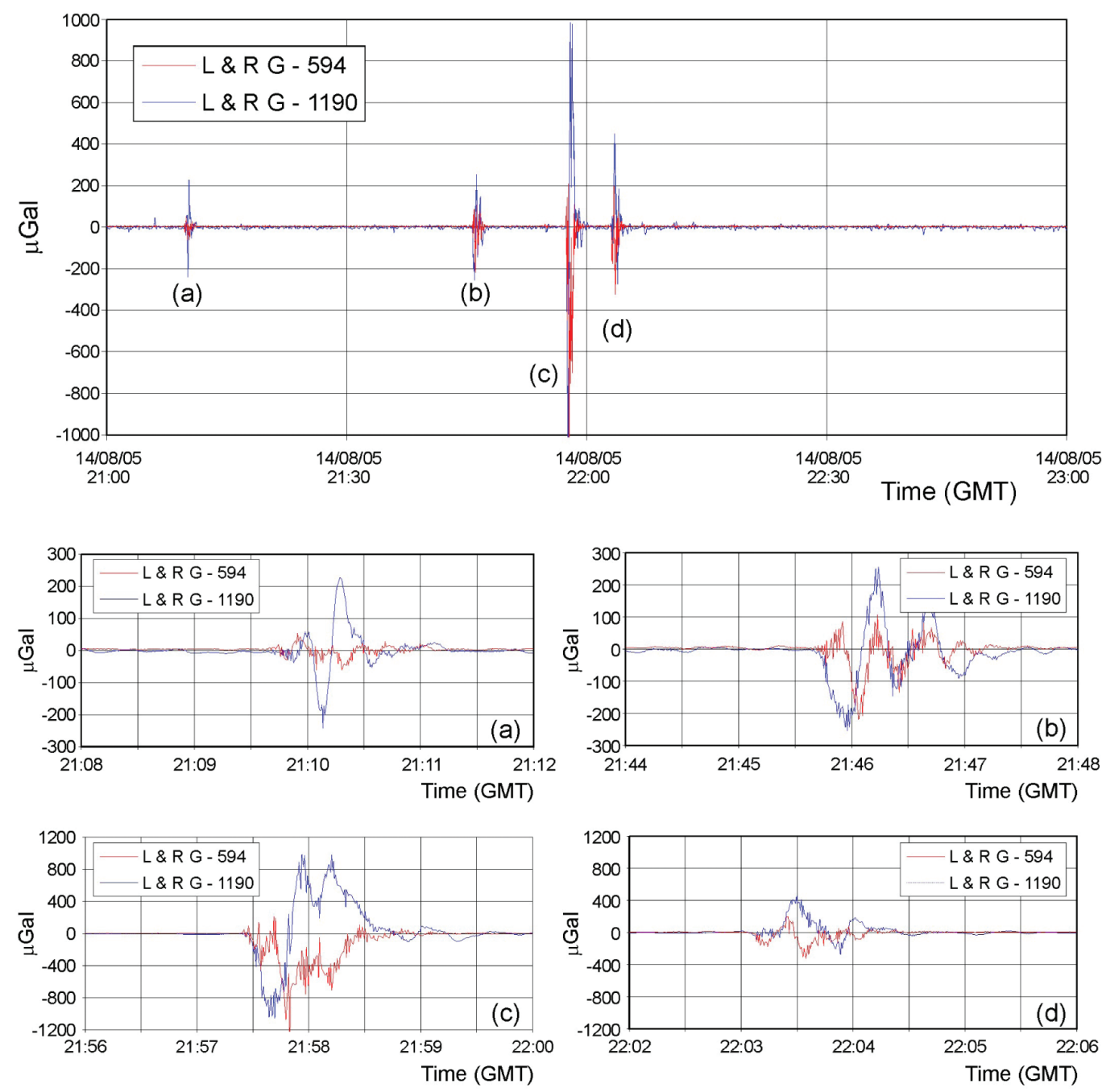

Fig. 2a,b. Gravity data recorded by G-594 and G-1190 gravimeters on August 142005 between 21:00 $\div$ 23:00 (GMT) time period encompassing four gravity fluctuations (upper graph). In the lower panels, from top to bottom are shown the raw gravity recordings by G-594 and G-1190 gravimeters relative to four 4-minute periods beginning respectively at 21:08 (a), 21:44 (b), 21:56 (c) and 22:02 (d), August 14, 2005. Gravity fluctuations spanning a wide range of periods (from 1 second to about $30 \mathrm{~s}$ ), duration ranges between 60 and $120 \mathrm{~s}$ and amplitude ranges between about 200 and about $2000 \mu$ Gal peak-to-peak (lower four graphs).

northern flank of the volcano, about $15 \mathrm{~km}$ from SLN gravity station (table I). Another gravity event with the same characteristics was recorded on 24 August 2005, when a single earthquake (no swarm) with magnitude of 2.7 and hypocenter in the south-east flank of Etna, occurred (INGV-CT; http://www.ct.ingv.it/GridTerremoti.htm; table I).

Vice versa, on other 13 short-time periods (table II), gravity fluctuations with about the same characteristic of previous events (as for am- 
Table I. Origin date and time (GMT time), elapsed time, amplitude and correlation factor of gravity fluctuations observed on 14 August 2005 during a seismic swarm of 18 earthquakes (magnitude $\mathrm{M}_{\mathrm{d}}$ ranging from 1.7 to 3.5 and hypocentral depth from about 1 to $3 \mathrm{~km}$ ) with the epicentre on the northern flank of the volcano, about $15 \mathrm{~km}$ from SLN gravity station and on 24 August, 2005 when an earthquake with magnitude of 2.7 and hypocenter in the south-east flank of Etna, occurred. In the last three right columns are shown: region, origin date and time (GMT time) and magnitude of coincident seismic events localized by INGV-CT. The seismic events analyzed in the following are highlighted in bold.

\begin{tabular}{|c|c|c|c|c|c|c|c|c|}
\hline \multirow[t]{2}{*}{ Date } & \multicolumn{2}{|c|}{$\begin{array}{l}\text { Origin date } \\
\text { and time } \\
\text { of gravity } \\
\text { fluctuations } \\
\text { (GMT) }\end{array}$} & \multirow[t]{2}{*}{$\begin{array}{c}\text { Amplitude } \\
\max (\mu \mathrm{Gal}) \\
\text { LCR1190 }\end{array}$} & \multirow[t]{2}{*}{$\begin{array}{c}\text { Amplitude } \\
\max (\mu \mathrm{Gal}) \\
\text { LCR } 594\end{array}$} & \multirow[t]{2}{*}{$\begin{array}{l}\text { Correlation } \\
\text { factor }\end{array}$} & \multirow[t]{2}{*}{ Region } & \multirow[t]{2}{*}{$\begin{array}{l}\text { Origin date } \\
\text { and time of } \\
\text { earthquake } \\
\text { (GMT) }\end{array}$} & \multirow[t]{2}{*}{$\begin{array}{c}\text { Magnitude } \\
M_{d}\end{array}$} \\
\hline & Start & $\begin{array}{l}\text { Elapsed } \\
\text { time }(m\end{array}$ & & & & & & \\
\hline $14 / 08 / 2005$ & 21:09 & 1 & 500 & 100 & -0.2 & Etna-N flank & 21:09:04.47 & 2.6 \\
\hline $14 / 08 / 2005$ & 21:45 & 2 & 500 & 300 & 0.3 & Etna-N flank & 21:45:04.18 & 2.9 \\
\hline $14 / 08 / 2005$ & $21: 57$ & 2 & 1800 & 1100 & -0.3 & Etna-N flank & $21: 56: 48.58$ & 3.5 \\
\hline $14 / 08 / 2005$ & $22: 02$ & 1 & 700 & 600 & -0.2 & Etna-N flank & $22: 02: 25.51$ & 3.1 \\
\hline $24 / 08 / 2005$ & 09:02 & 2 & 100 & 100 & 0.3 & Etna- SE flank & 09:02:26.92 & 2.7 \\
\hline
\end{tabular}

Table II. Origin date and time (GMT time), elapsed time, amplitude (during the large earthquakes labelled both signals have equal amplitude) and correlation factor of gravity fluctuations observed during August-September 2005 period simultaneously with large worldwide earthquakes (teleseisms). Region, origin date and time (GMT time) and magnitude of coincident earthquakes localized by USGS are also shown in the last three right columns. The empty cells are because when earthquake magnitude is lower than 4 , it is not possible to discriminate the earthquake that induced gravity fluctuations. The seismic event presented in the following are highlighted in bold.

\begin{tabular}{|c|c|c|c|c|c|c|c|}
\hline \multirow[t]{2}{*}{ Date } & \multicolumn{2}{|c|}{$\begin{array}{l}\text { Origin date } \\
\text { and time } \\
\text { of gravity } \\
\text { fluctuations } \\
\text { (GMT) }\end{array}$} & \multirow[t]{2}{*}{$\begin{array}{c}\text { Amplitude } \\
\max (\mu \mathrm{Gal}) \\
\text { LCR } 1190\end{array}$} & \multirow[t]{2}{*}{$\begin{array}{l}\text { Correlation } \\
\text { factor }\end{array}$} & \multirow[t]{2}{*}{ Region } & \multirow[t]{2}{*}{$\begin{array}{l}\text { Origin date } \mathrm{N} \\
\text { and time of } \\
\text { earthquake } \\
(\mathrm{GMT})\end{array}$} & \multirow[t]{2}{*}{$\begin{array}{c}\text { Magnitude } \\
M_{d}\end{array}$} \\
\hline & Start & $\begin{array}{l}\text { Elapsed } \\
\text { time (min) }\end{array}$ & & & & & \\
\hline 03/08/2005 & $11: 31$ & 95 & 120 & 0.925 & Nicaragua & 03/08/2005-11:03 & 35.9 \\
\hline $07 / 08 / 2005$ & $02: 57$ & 25 & 100 & 0.875 & South Africa & 07/08/2005-02:17 & $7 \quad 5.5$ \\
\hline $07 / 08 / 2005$ & $12: 56$ & 50 & 30 & 0.654 & & & \\
\hline 09/08/2005 & $06: 46$ & 50 & 25 & 0.605 & & & \\
\hline 09/08/2005 & $15: 32$ & 50 & 30 & 0.605 & Iran? & 09/08/2005-14:20 & $0 \quad 4.2$ \\
\hline $11 / 08 / 2005$ & $10: 26$ & 50 & 40 & 0.737 & & & \\
\hline $16 / 08 / 2005$ & 03:20 & 170 & 1500 & 0.985 & Japan & 16/08/2005-02:46 & 67.0 \\
\hline $24 / 08 / 2005$ & 11:04 & 35 & 100 & 0.818 & & & \\
\hline $26 / 08 / 2005$ & $18: 25$ & 40 & 240 & 0.848 & East Africa & 26/08/2005-18:16 & $6 \quad 6.2$ \\
\hline $27 / 08 / 2005$ & $19: 22$ & 30 & 30 & 0.512 & & & \\
\hline $30 / 08 / 2005$ & $18: 28$ & 40 & 180 & 0.823 & Japan & $30 / 08 / 2005-18: 10$ & $\begin{array}{ll}0 & 5.9\end{array}$ \\
\hline $25 / 09 / 2005$ & $14: 15$ & 60 & 35 & 0.681 & & & \\
\hline $26 / 09 / 2005$ & 02:09 & 140 & 1800 & 0.973 & Perù & $26 / 09 / 2005-01: 55$ & $5 \quad 7.5$ \\
\hline
\end{tabular}




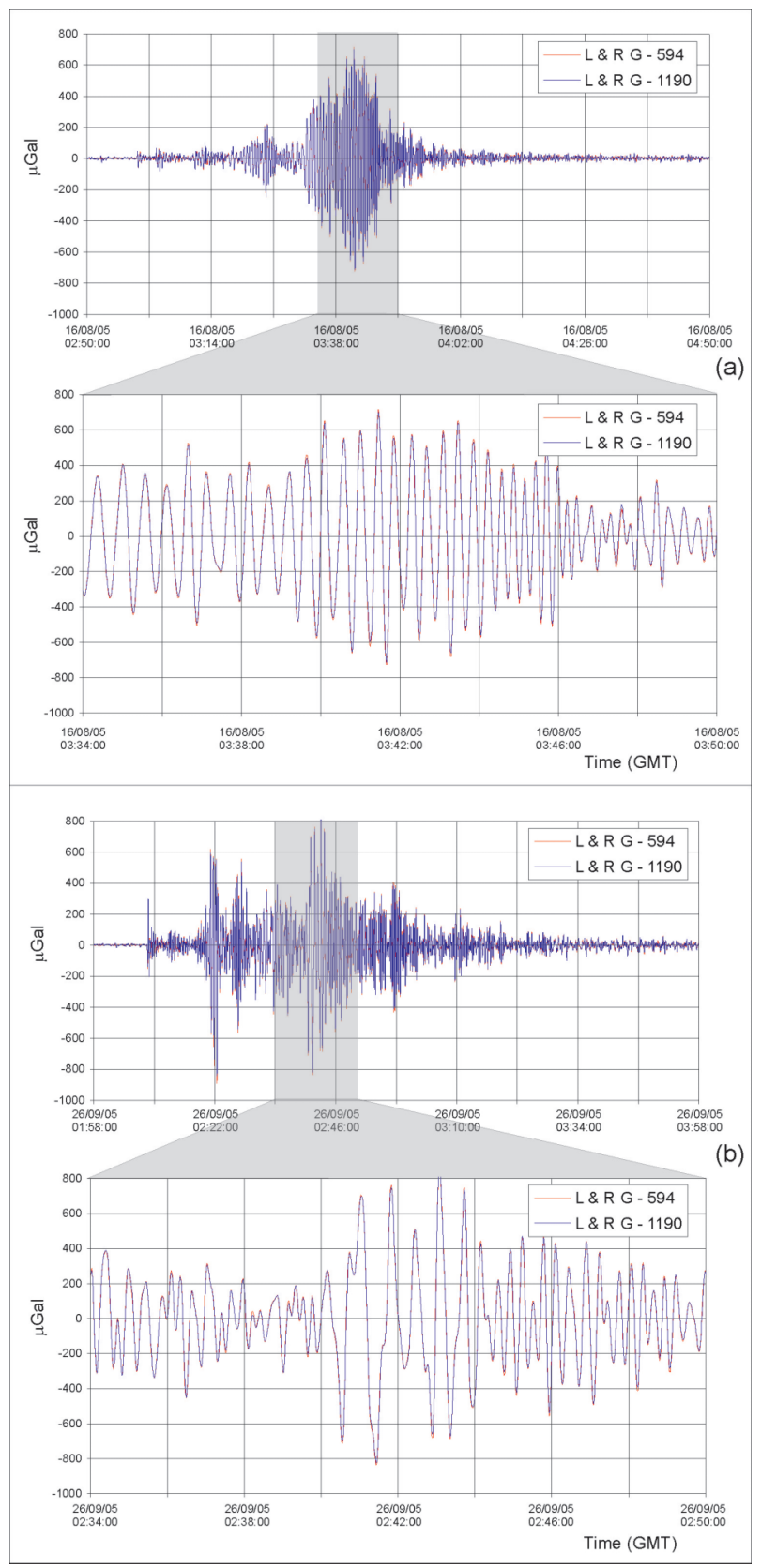

Fig. 3a,b. Gravity data recorded by G-594 and G-1190 gravimeters on August 162005 between 02:50 $\div$ 04:50 (GMT; graph a in fig. 3) time period encompassing a gravity fluctuation during a strong earthquake in Japan (Magnitude 7) and gravity data recorded by G-594 and G-1190 gravimeters on September 262005 between $01: 58 \div 03: 58$ (GMT; graph b in fig. 3) time period encompassing a gravity fluctuation during a strong earthquake in Perù (Magnitude 7.5). Grey strips highlight the periods over which the figures was enlarged. 
plitude and spectral content of the main components) but lasting 1 to $3 \mathrm{~h}$, were observed simultaneously with high-energy worldwide earthquakes (USGS; http://earthquake.usgs.gov/recenteqsww/Quakes/quakes_all.html). The events with greater amplitude and duration were recorded on 16 August and on 26 September 2005 (fig. $3 \mathrm{a}, \mathrm{b})$ during two strong earthquakes in Japan $(M$ 7 ) and Peru (M 7.5), respectively.

\section{Data analysis}

The experiment carried out on Etna, lasting 60 days, is not suitable for the study of phenomena with slow evolution (periods more than a few days). Moreover, long period oscillations were not analyzed in this study since complementary parameters such as pressure, tempera- ture and ground deformation (as stated before, these influence only the long period components) were not assessed and thus their effect on gravity data cannot be corrected.

The 2-month gravity data were corrected for the effect of earth tides (modeled through the Eterna 3.30 data processing package; Wenzel, 1996) and instrumental drift (modeled as a first degree curve for G-1190 and as second degree curve for G-594, respectively).

After these corrections were accomplished, the background noise level and the spectral content of both sequences were characterized. Figure 4 presents a two hour record acquired with both gravimeters on 10 August 2005, between 11:00 and 13:00 GMT. The mean background higher-frequency noise is within about $5 \mu \mathrm{Gal}(\mathrm{G}-594)$ and about 10 $\mu \mathrm{Gal}(\mathrm{G}-1190)$.
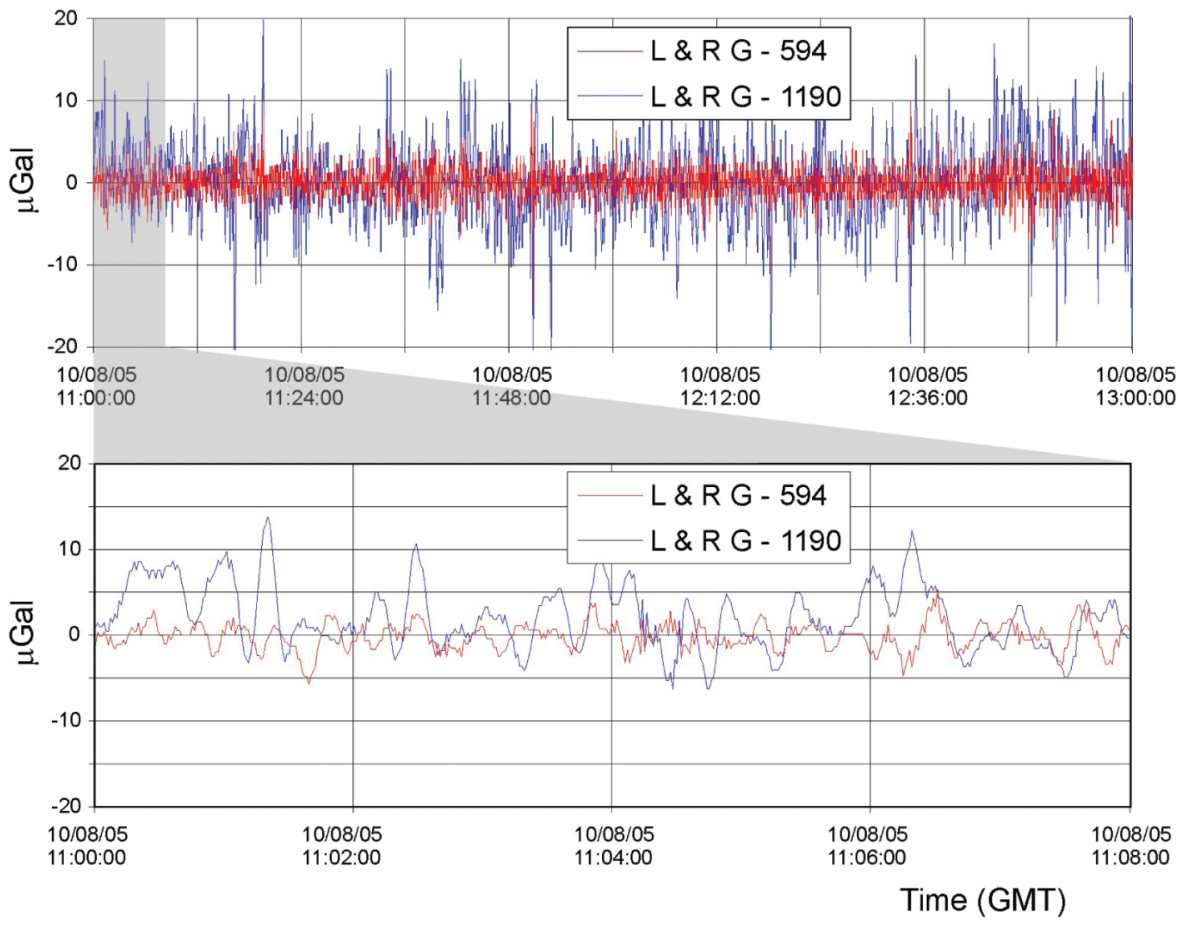

Fig. 4. Two-hour raw gravity data recorded on August, 2005 between 11:00 $\div$ 13:00 (GMT) time interval using G-594 and G-1190 gravimeters. The figure shows the background higher-frequency noise at SLN gravity station of both gravimeters that is within about $5 \mu \mathrm{Gal}(\mathrm{G}-594)$ and about $10 \mu \mathrm{Gal}$ (G-1190). Grey strips highlight the periods over which the upper figure was enlarged. 

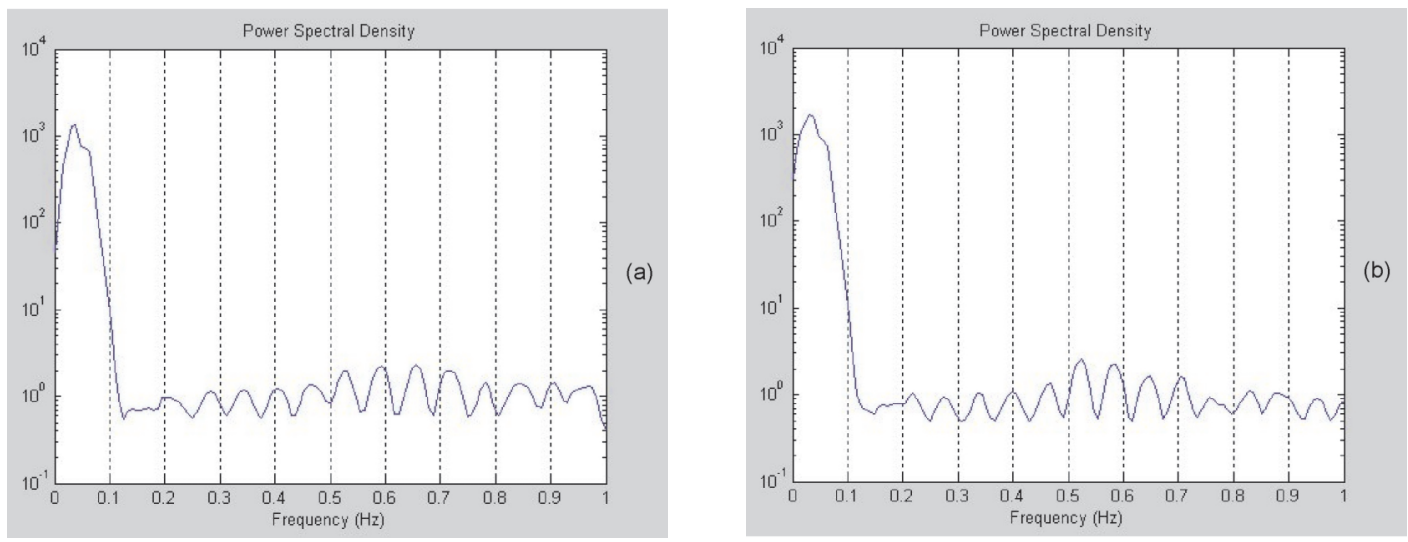

Fig. 5a,b. Power spectral densities of both signals (G-594; a and G-1190; b) performed on gravity sequences recorded on Etna during 01 August - 29 September 2005 time interval.
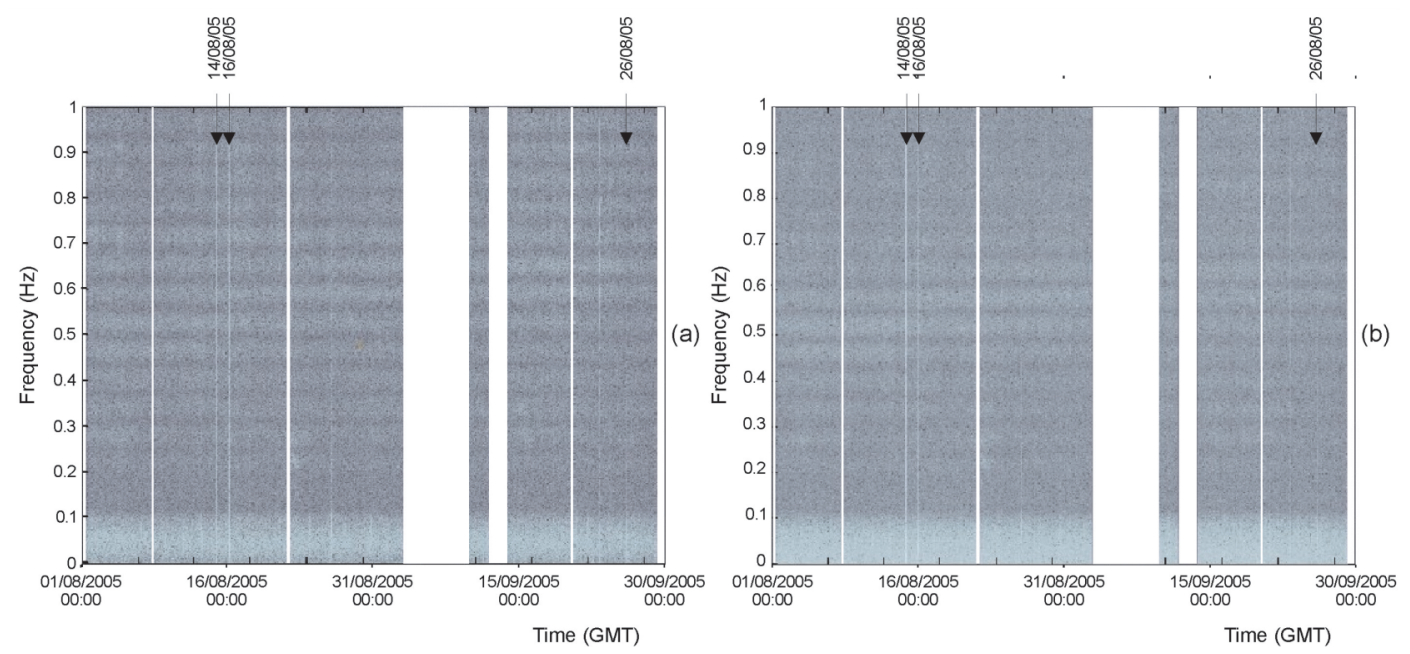

Fig. 6a,b. Periodogram of both data sets recorded on Etna during 01 August - 29 September 2005 period using G-594 (a) and G-1190 (b) gravimeters. For the choice of the time domain window, a three-hour long window was applied to the data and was successively shifted by one hour. The occurrence of a seismic swarm on Etna and large worldwide earthquakes recorded during the period are indicated on the top of the upper figure.

The power spectra of both sequences are shown in fig. 5. The results of the Fourier analysis show steady strong peaks centred at $0.05 \mathrm{~Hz}$ ( $T$ equal $20 \mathrm{~s}$; fig. 5a) and at $0.06 \mathrm{~Hz}$ ( $T$ equal 15 s; fig. 5b) for G-1190 and G-594 gravimeters, respectively. In order to examine the temporal variation of the spectrum of the two signals, the frequency-time spectrograms were computed 


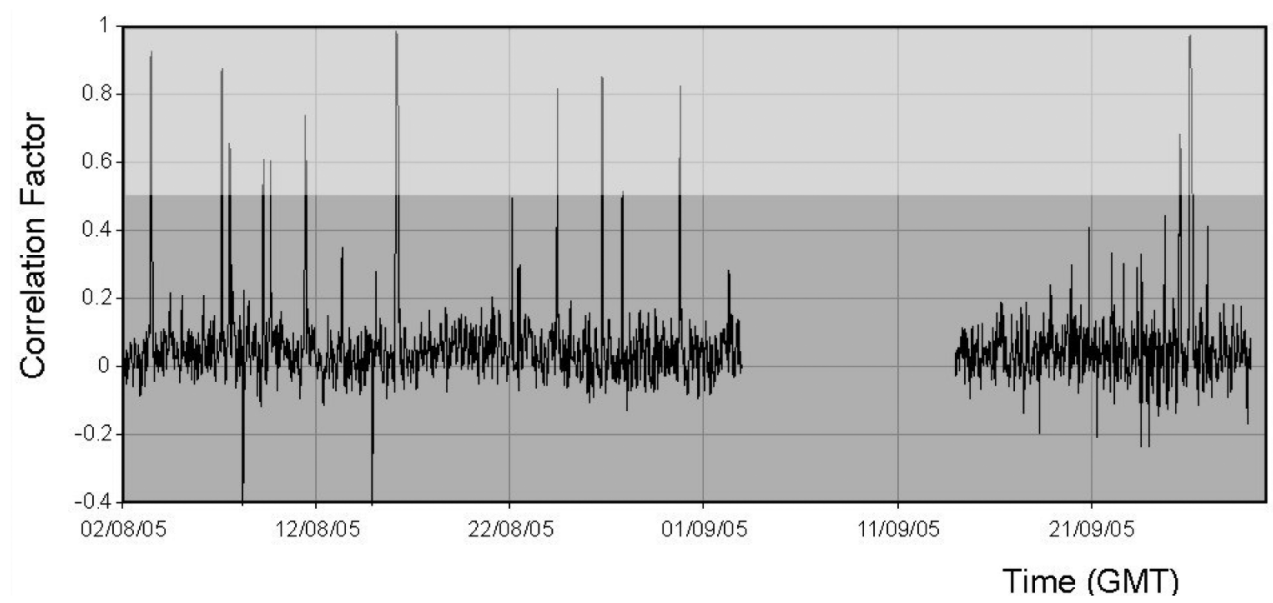

Fig. 7. Time changes of the correlation factor between the two gravity sequences recorded on Etna during 01 August - 29 September 2005 period. A sliding 1-hour window (50\% overlap) was used for the calculation.

(G-594 - fig. 6a; G-1190 - fig. 6b). A three-hour long window was applied to the data and was subsequently shifted by one hour. The occurrence of a seismic swarm on Etna and stronger teleseisms recorded during the period are indicated on the top of fig. 6. Results disclose a dominant horizontal strip centered in the lower part of both spectrograms (up to $0.07 \div 0.08 \mathrm{~Hz}$ ) and persistence throughout the 2-month period of observation. Other lines are weak and scarcely recognizable as spectral peaks. No meaningful variation of signal frequency content occurred during the recording period.

Next, we calculate the correlation between the two gravity sequences, using a 1-hour window sliding along the signal with $50 \%$ overlap (fig. 7). A marked correlation (factor up to 0.99 ) occurs on 13 short-time periods, simultaneously with high-energy large worldwide earthquakes (table II). Over the rest of the considered time interval, including the time interval encompassing the seismic swarm on Etna, the amplitude of the correlation never reaches values higher than 0.3 .

As a further step in our analysis, we focused on time windows spanning the occurrence of local and large worldwide earthquakes. It is worth stressing that the same kind of analysis
Table III. Correlation indexes between original gravity signal (in bold) recorded on 14 August, 2005 between $21: 44 \div 21: 48$ (GMT) using L\&R D-594 and G-1190 gravimeters and between five detail levels obtained through the wavelet multiresolution analysis.

\begin{tabular}{ccc}
\hline \hline $\begin{array}{c}\text { Sensor } \\
\text { L\&R G-594 }\end{array}$ & $\begin{array}{c}\text { Correlation } \\
\text { index }\end{array}$ & $\begin{array}{c}\text { Sensor } \\
\text { L\&R G-1190 }\end{array}$ \\
\hline Original signal & $\mathbf{0 . 2 6 9 5}$ & Original Signal \\
D1 Level & 0.0216 & D1 Level \\
D2 Level & -0.0286 & D2 Level \\
D3 Level & 0.1342 & D3 Level \\
D4 Level & 0.1278 & D4 Level \\
D5 Level & 0.6081 & D5 Level \\
\hline
\end{tabular}

has been applied on every time period encompassing the seismic-induced gravity fluctuations recorded and the results were always comparable. So, in the following, only the results of analysis performed on two time intervals encompassing two seismic events among those listed in tables I and II are presented and discussed (figs. $2 \mathrm{~b}$ and $3 \mathrm{a}$ ).

In particular, we focused on a short-time period (4 min) on 14 August 2005 between $21: 44 \div 21: 48$ (GMT) time interval encompassing 
(a)
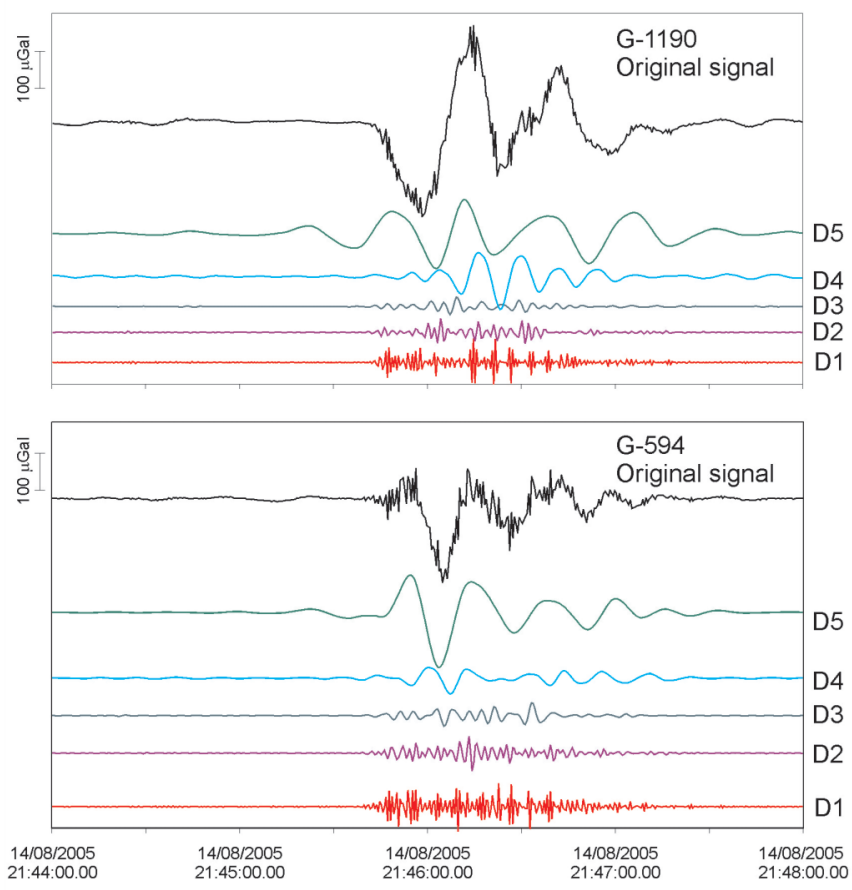

(b)
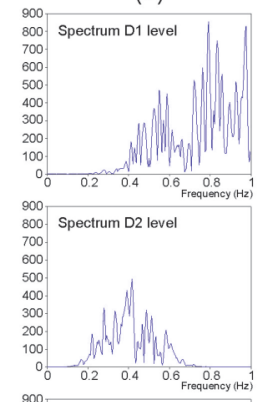

sol
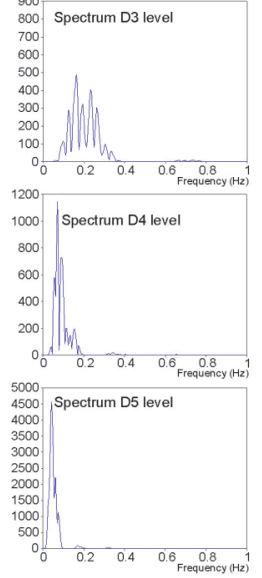

(c)

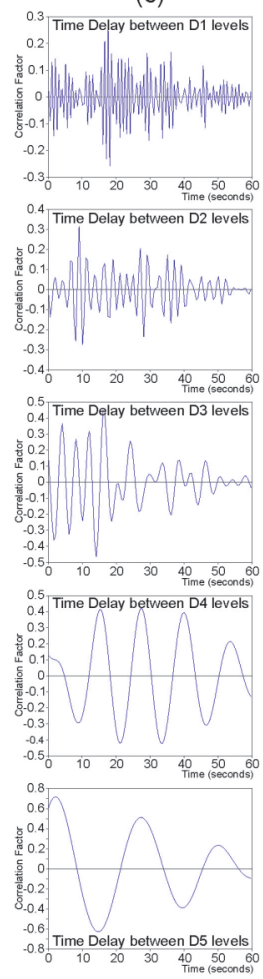

Fig. 8a,b. Wavelet multiresolution analysis performed on a short-time-span (4 minutes) continuous gravity sequences recording on 14 August 2005 between $21: 44 \div 21: 48$ (GMT) by G-594 and G-1190 gravimeters affected by one gravity fluctuation whose amplitude ranges between $250-400 \mu$ Gal peak-to-peak, observed during the seismic swarm on 14 August 2005. The signals shown in the left panel (a), have been decomposed into five detail levels. Results of the spectral analysis of each detail level are shown in the middle of the figure (b), while the time correlation analysis is presented in the panel c.

one of the four gravity fluctuations (fig. 2b; table I) and on 2-hour selected time interval on $16 \mathrm{Au}-$ gust 2005 between $02: 50 \div 04: 50$, when one of the stronger earthquakes of considered period took place (fig. 3a; table II). Moreover, 30minute gravity data recorded on 10 August 2005 between $02: 00 \div 02: 30$ (GMT) time interval, during a «quiet period», were analyzed for comparison. Using wavelet multi-channel filter analysis to the short time-span periods as stated above, we filtered each gravity sequence into different narrow frequency bands. The advantage of analysing a signal with the wavelet multiresolution decomposition, considered as a band pass filter, is that it allows to filter the signals into very narrow band with good frequencies response and without introducing a phase lag.

The short time-span sequences were decomposed into different detail levels (corresponding to different frequency bands), ranging between 1 to 5 (14 August 2005; between 21:44 $\div 21: 48$; fig. 8a), 1 to 10 (16 August 2005, between $02: 50 \div 04: 50$; fig. 9 a) and 1 to 8 (10 August 2005 , between $02: 00 \div 02: 30$; fig. 10a), depending on the length of the considered time window and the type of wavelet basis used (Daubechies, 1992). The spectral analyses, showing the frequency content of each detail level, are plotted in figs. $8 \mathrm{~b}, 9 \mathrm{~b}$ and $10 \mathrm{~b}$.

In order to investigate possible correlations 


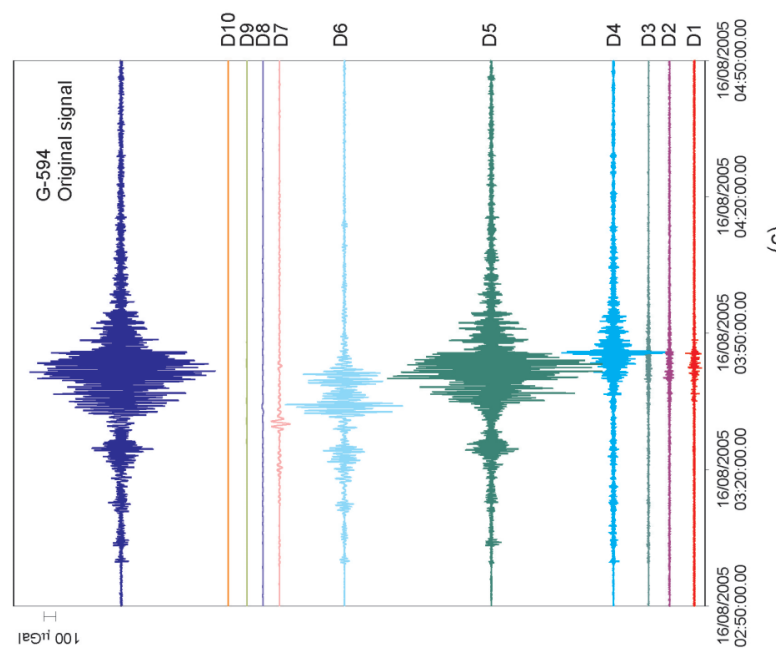

త్ర

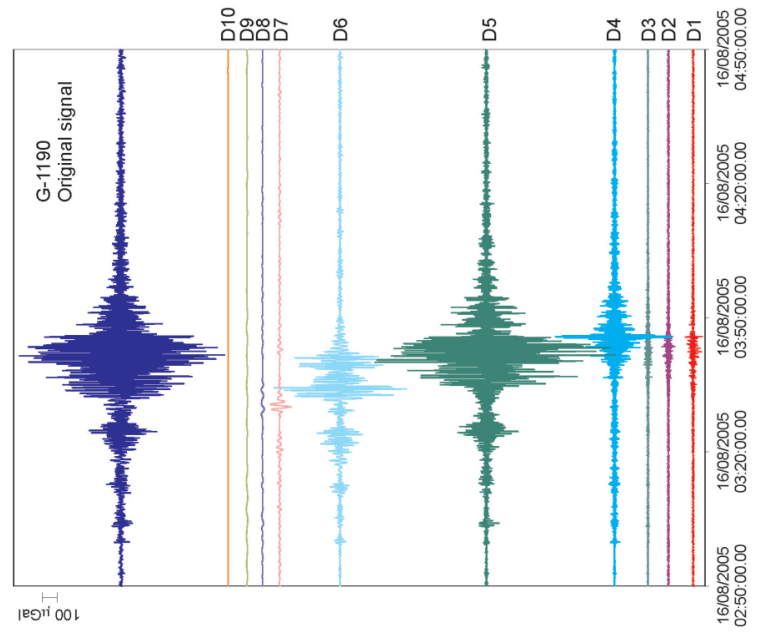

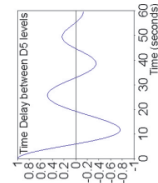
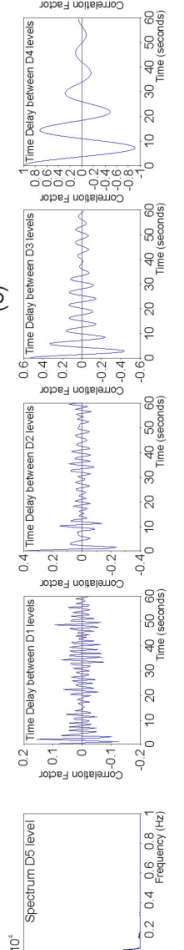

가유.
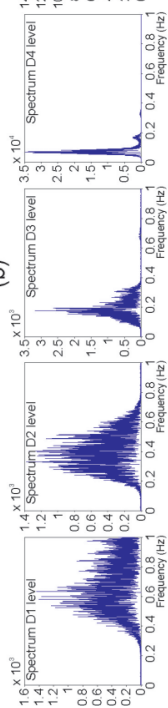

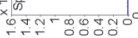

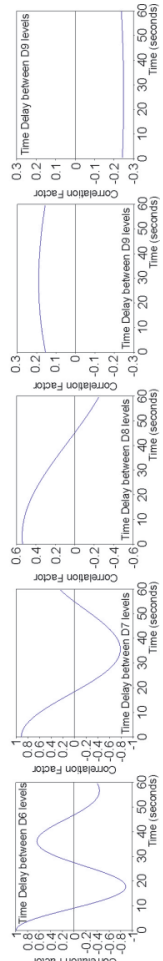

究专递

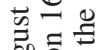



㓂气

달

bo $8 \dot{0} 0$

ำ 일

8 에.

들

\& 0 웡

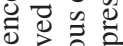

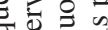

品

충 융

สํㅠㄹ

㛡

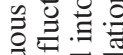

记

.

해 है

范 娄.

증

c。원

용

क.

ช

离

咅

के 20

豞可

ธิ จํํ융

을.

ํㅣㄹ

를

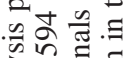

皮

ส

₹

.롱

है응

ए广

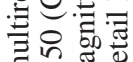

范导

过氜

ए.

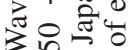

ن. $\Xi$

응

बै ญ्त

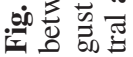


Table IV. Correlation indexes between original gravity signal (in bold) recorded on 16 August, 2005 between $02: 50 \div 04: 50$ (GMT) using L\&R D-594 and G-1190 gravimeters and between ten detail levels obtained through the wavelet multiresolution analysis.

\begin{tabular}{ccc}
\hline $\begin{array}{c}\text { Sensor } \\
\text { L\&R G-594 }\end{array}$ & $\begin{array}{c}\text { Correlation } \\
\text { index }\end{array}$ & $\begin{array}{c}\text { Sensor } \\
\text { L\&R G-1190 }\end{array}$ \\
\hline Original signal & $\mathbf{0 . 9 9 6 7}$ & Original Signal \\
D1 Level & 0.1162 & D1 Level \\
D2 Level & 0.3879 & D2 Level \\
D3 Level & 0.5423 & D3 Level \\
D4 Level & 0.9949 & D4 Level \\
D5 Level & 0.9988 & D5 Level \\
D6 Level & 0.9968 & D6 Level \\
D7 Level & 0.9132 & D7 Level \\
D8 Level & 0.5389 & D8 Level \\
D9 Level & 0.1543 & D9 Level \\
D10 Level & -0.2441 & D10 Level \\
\hline
\end{tabular}

over each frequency band on the three periods considered, the cross-correlation analysis between each detail level of both signals, were calculated. Figure 8 a shows a short time-span (4 min) continuous gravity recording between $21: 44 \div 21: 48$ (GMT time) affected by one selected event whose amplitude ranging between 250-400 $\mu$ Gal peak-to-peak, observed during the seismic swarm on 14 August 2005. Through the wavelet multiresolution analysis, the signals were filtered into 5 detail levels. Results of spectral analysis are shown in fig. 8b. Cross-correlation indexes between the five detail levels are reported in table III. Results of the cross-correlation analysis, defining the phase lag or delay time between the two signals, are presented in fig. 8c. As labelled in table III, poor correlation indexes were found between the original signals and also between D1, D2, D3 and D4 detail levels. What's more, in D3 and D4 detail levels the correlation indexes increase (values higher than 0.3 ) with a time delay of 2 and $9 \mathrm{~s}$, respectively (fig. 8c). Only the D5 levels, corresponding to the frequency band ranging between $0.05 \mathrm{~Hz}$ and $0.01 \mathrm{~Hz}$ (period ranging between about 20 and $100 \mathrm{~s}$ ), show a correlation index up to 0.6081 .

Figure 9a shows 2-hour continuous gravity recording between 02:50 $\div$ 04:50 (GMT) affect- ed by one gravity fluctuation observed during a large worldwide earthquake on 16 August 2005 in Japan (M 7). After wavelet multiresolution analysis was accomplished, ten detail levels were obtained. As labelled in table IV, a remarkable correlation was found between original signals and between detail levels from second to eighth. The highest correlation index, up to 0.9988 , was found for D5 detail levels corresponding to the frequency band centered around $0.04 \mathrm{~Hz}$ (period of about $25 \mathrm{~s}$ ). Negligible correlation indexes was found only between D1, D9 and D10 levels, for all values of the delay time (fig. 9c). So the correlation between signals decreases only for the highest and lowest frequencies band.

Finally, fig. 10a shows a short-lasting (30 min) continuous gravity recording on 10 August 2005 between $02: 00 \div 02: 30$ (GMT time) during a quiet period. After the multiresolution analysis of both gravity sequences was performed, and eight detail levels were obtained, each frequency band was studied. Generally, the amplitudes of the components recorded by G-1190 are higher than the amplitudes of the signal components recorded by G-594 (fig 10a). On the other end, the amplitude of each component of both signals decreases up to 1 order of magnitude with respect to the period encompassing the seismic events.

Instantaneous cross-correlation indexes between the eight detail levels are reported in table V. Results of spectral analysis and the time crosscorrelation analysis are presented in fig. 10b,c. As labelled in table $\mathrm{V}$, negligible correlation indexes were found between the original signals and also between the D3, D4, D5, D6 and D8 detail levels, for all values of the delay time (fig. 10c). Instead, a correlation index, higher than 0.3 , was found between D1 and D2 levels (table $\mathrm{V})$ corresponding to a frequency band ranging between $0.1 \mathrm{~Hz}$ (period equal $10 \mathrm{~s}$ ) and $1 \mathrm{~Hz}$ (which corresponds to the Nyquist frequency) and between D7 levels corresponding to a frequency band ranging between 0.02 and $0.01 \mathrm{~Hz}$ (period ranging between 50 and $100 \mathrm{~s}$ ).

\section{Discussion}

In this paper 2-month gravity sequences recording on Etna by two different gravimeters 


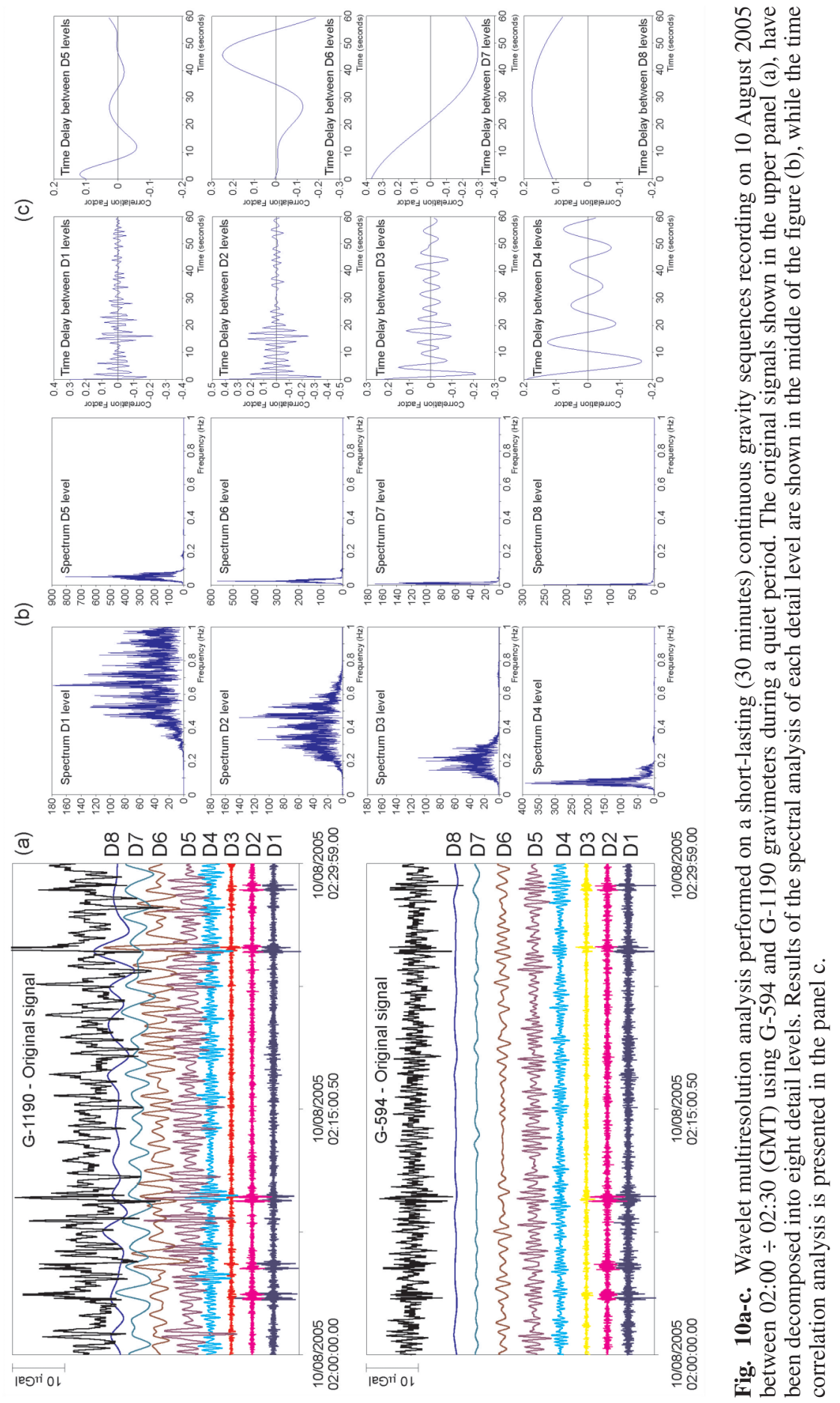


Table V. Correlation indexes between original gravity signal (in bold) recorded on 10 August, 2005 between 02:00 $\div 02: 30$ (GMT) using L\&R D-594 and G-1190 gravimeters and between eight detail levels obtained through the wavelt multiresolution analysis.

\begin{tabular}{ccc}
\hline $\begin{array}{c}\text { Sensor } \\
\text { L\&R G-594 }\end{array}$ & $\begin{array}{c}\text { Correlation } \\
\text { index }\end{array}$ & $\begin{array}{c}\text { Sensor } \\
\text { L\&R G-1190 }\end{array}$ \\
\hline Original signal & $\mathbf{0 . 1 3 6 7}$ & Original Signal \\
D1 Level & 0.3020 & D1 Level \\
D2 Level & 0.4426 & D2 Level \\
D3 Level & 0.2335 & D3 Level \\
D4 Level & 0.1935 & D4 Level \\
D5 Level & 0.0973 & D5 Level \\
D6 Level & 0.0072 & D6 Level \\
D7 Level & 0.3690 & D7 Level \\
D8 Level & 0.1105 & D8 Level \\
\hline
\end{tabular}

installed side-by-side were analyzed. The results of the spectral analysis of both records indicated a dominance of a frequency band centered around $0.05 \mathrm{~Hz}$ and $0.06 \mathrm{~Hz}$ (period equals 15 and $20 \mathrm{~s}$ ). Spectrograms of data sequences indicated a persistence of this frequency band through the 2-month period of observations and a negligible change of frequency content elsewhere, comprising the period in which earthquakes took place. Furthermore, results of correlation analyses show a marked correlation (up to 0.99 ) in correspondence of 13 highlight periods and a negligible correlation elsewhere. This feature strongly suggests that during the 13 short-time periods a common source (corresponding to large teleseismic events) activated the gravity oscillations observed in both signals. During the rest of the period under study, the signals of both gravimeters were significantly different. The value of the correlation factor never reached values higher than 0.3 . This means that gravimeters oscillate with their characteristic period and respond to the external excitations in an uncorrelated manner, as strongly emerges from the wavelet multiresolution analysis performed and presented in figs. 8-10.

In the light of these results, together with the fact that the meters were installed side-by- side, thus identical path- and site-effects over the seismic perturbation are to be assumed, imply that only instrument-dependent effects (i.e. mechanical perturbation of the sensor device caused by earthquakes) are prevailing when some dominant seismic frequencies excite the meters. The mechanical perturbation of the gravity sensors, due to some dominant frequencies on the occasion of seismic events, can last several hours for large worldwide earthquakes and a few minutes for local earthquakes. Moreover, results of analysis indicated that there are some differences in the behaviour of two meters when different seismic frequencies influence measurement systems. When high frequency seismic waves (local earthquakes) excite the meters, instrument-dependent fluctuations, spanning a wide range of periods (from $1 \mathrm{~s}$ to about $30 \mathrm{~s}$ ) and strongly depending on the single gravimeter, are predominant. Vice versa, when perturbed by low-frequency seismic waves (teleseisms), the gravimeters react according to a more common feature. The gravity meters had strikingly similar responses (correlation factor up to 0.99). Such a difference is because a large worldwide earthquake tends to have more spectral power in lower frequencies. The period of oscillation relative to some large earthquake components corresponds exactly to the main frequency resonance of the instruments. Most likely, the teleseisms drive the gravimeters to their common resonant frequency causing synchronisms of the signals. It is not obvious from the present analysis which seismic component, vertical or horizontal, has a greater effect on the instrumental accelerations.

To confirm the latter hypothesis, fig. 11a,b shows the seismogram traces recorded by longperiod seismic networks of INGV-CT on 16 August and on 26 September 2005 respectively, during two strong earthquakes in Japan $(M 7$; fig. 11a) and Peru ( $M 7.5$; fig. 11b). We selected these two events because their effects observed by gravity meters are longer (duration about 140 and $170 \mathrm{~min}$, respectively) and more energetic (maximum amplitude about 1500 and $1800 \mu \mathrm{Gal}$, respectively) than the other events observed. As can be seen in fig. 11a,b, the main teleseismic recordings have dominant compo- 

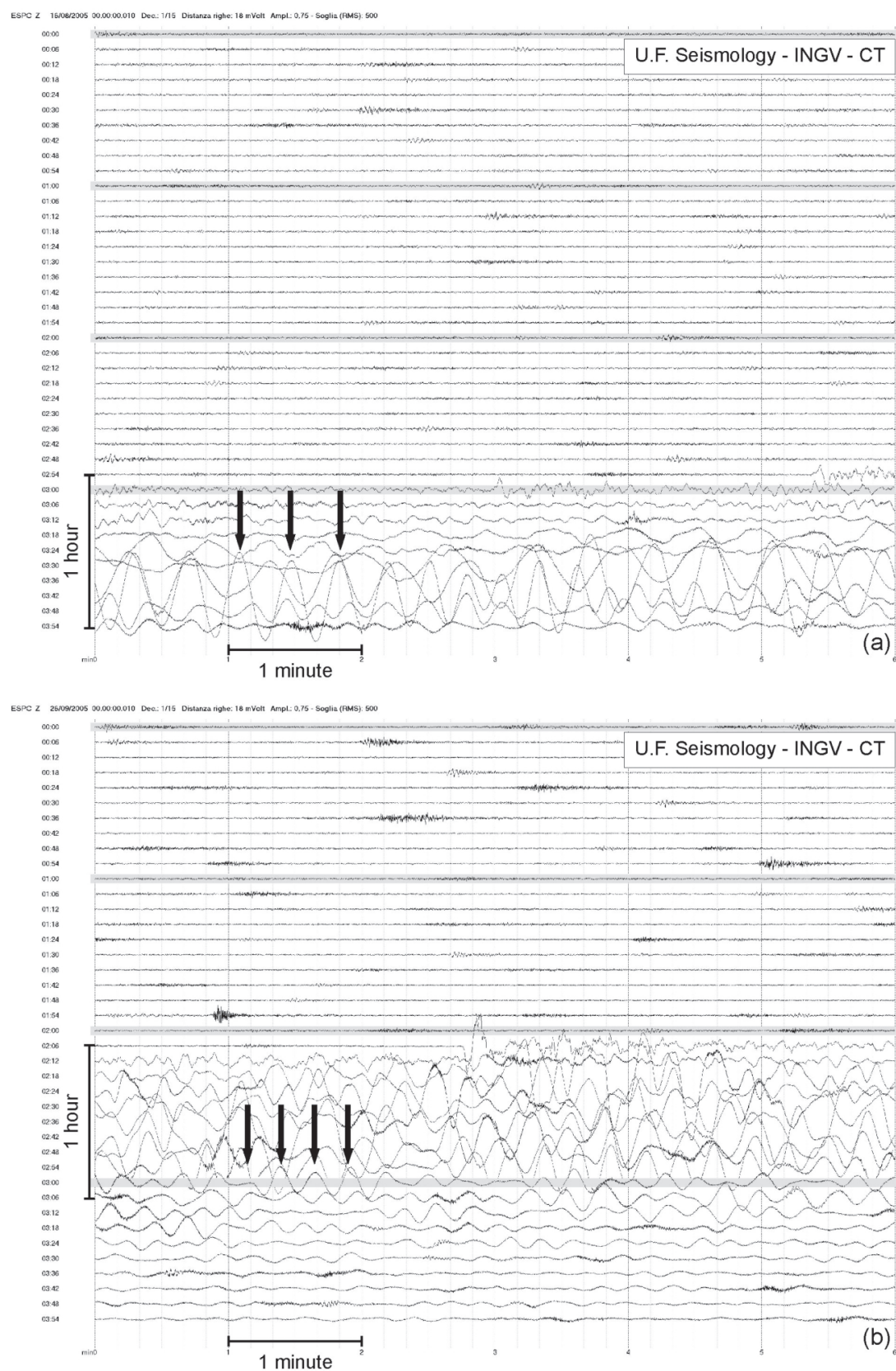

Fig. 11a,b. Seismogram traces recorded by a long-period seismic station of the INGV-CT network. Long period waves are due to strong earthquakes in Japan (August 16 2005; magnitude 7 - upper panel) and Peru' (September 26 2005; magnitude 7.5 - lower panel). As can be seen in figures $11 \mathrm{a}-\mathrm{b}$, the teleseismic recordings have dominant components whose period is about 15-20 s and corresponds exactly to the period of main gravity oscillations. 
nents whose period is about $15-20 \mathrm{~s}$ and correspond exactly to the period of main gravity oscillations recorded simultaneously (fig. 11a,b). Furthermore, this period ( $T$ equal 15-20 s) corresponding to the fundamental mode of oscillation of the spring sensor for L\&R model $G$ (Torge, 1989) also includes the highest mode of the Seismic Free Oscillations (SFO) of the Earth. So the effect of the Earth's SFO can also be hypothesized.

Finally, we can also assess how a different earthquake magnitude influences the mechanical behaviour of both gravimeters. It is worth stressing that, although in the considered period about 90 local earthquakes of magnitude $\mathrm{M}_{\mathrm{d}}$ ranging between 0.2 and 3.5 and about 4500 worldwide earthquakes of magnitude ranging between 1.5 and 7.5 were recorded (seismic parameters were taken from the USGS and INGV-CT web sites), to trigger gravity fluctuations such as those discussed before, the magnitude threshold for local events approximately $15 \mathrm{~km}$ distant from the gravity station, is about $M_{d}=2$. For the most distant teleseisms, the magnitude threshold seems to be around $M=4$. As the earthquake magnitude gets lower, despite $M=2$ for local events and $M=4$ for most distance events, respectively, the mechanical shock of the gravimeters caused by earthquakes suddenly decreases and it is not possible to discriminate the earthquake-induced gravity accelerations from the «normal noise».

\section{Conclusions}

The assessment of high-frequency data (2 da$\mathrm{ta} / \mathrm{s})$, means the enlargement of the observable range towards phenomena with higher rates of evolution, more pertinent to volcano monitoring. This study, thanks to high measurement frequency, allowed the correlation of short-lasting gravity fluctuations with seismic events.

In order to investigate the effects of seismicinduced acceleration on gravity meters, a time interval of contemporary records by two LaCoste \& Romberg G-594 and G-1190 was selected. Gravity records were analyzed for a time window spanning the occurrence of local and large worldwide earthquakes. Such oscillations are scarcely documented in the literature since previous continuous gravity recordings on active volcanoes (Davis, 1981; De Meyer et al. 1995; Berrino et al. 1997; Carbone et al. 2003) were made at unsuitable sampling rates to permit their assessment. The far-field effects produced by large earthquakes were evaluated on the gravity signals by Berrino et al., 2004. Continuous gravity measurements to determine coseismic gravity changes (Imanishi et al., 2004) or to study the Earth's free oscillations (Nawa et al., 1998) were carried out using superconducting gravimeters.

A limited experiment conducted using only two meters, allowed the characterization of the frequency response of LaCoste \& Romberg spring gravimeters when different seismic events occurred (local and large worldwide earthquakes). However there is insufficient information to deduce if mechanical perturbations are typical of all spring gravimeters or only those of LCR.

In conclusion, it can be stressed that large worldwide and strong local earthquakes can produce both real geophysical and instrumental signals, detectable by gravity meters. A quantitative study in order to split this effect might be very hard to pursue. Furthermore, if we consider the earthquake-induced gravity acceleration as an instrumental nature only, the outcome of this study represents an important step and it will allow the potential of continuous gravity studies to be used in the best way and the feedback from other observations to be optimized.

\section{Acknowledgements}

This work was developed in the frame of the TecnoLab, the Laboratory for the Technological Advance in Volcano Geophysics organized by INGV-CT and DIEES-UNICT. This study was performed with the financial support from the ETNA project (DPC-INGV 20042006 contract). Thanks are due to the ENI S.p.A AESI Dept. E\&P Division for making the gravity meters available. We are also grateful to Salvatore Alparone for providing the seismogram traces. 


\section{REFERENCES}

BERRINO, G. and U. RICCARDI (2004): Far-field gravity and tilt signals by large earthquakes: real or instrumental effects?, Pure, Appl. Geophys., 161, 1379-1397.

Berrino, G., G. Corrado, R. Magliuolo and U. RiccarDI (1997): Continuous record of the gravity changes at Mt. Vesuvius, Ann. Geofis., XL (5), 1019-1028.

BRANCA, S., D. CARBone and F. GReCo (2003): Intrusive mechanism of the 2002 NE-Rift eruption at Mt. Etna (Italy) inferred through continuous microgravity data and volcanological evidences, Geophys. Res. Lett., 30 (20) 2077, doi: 10.1029/2003GL018250.

Budetta, G., D. Carbone and F. Greco (1999): Subsurface mass redistribution at Mt. Etna (Italy) during the 1995-96 explosive activity detected by microgravity studies, Geophys. J. Int., 138, 77-88.

Carbone, D., G. Budetta, F. Greco and H. Rymer (2003): Combined discrete and continuous gravity observations at Mt. Etna, J. Volcanol. Geotherm. Res., 2581, 1-13.

Carbone, D., L. Zuccarello, G. Saccorotti and F. GreCO (2006): Analysis of simultaneous gravity and tremor anomalies observed during the 2002-2003 Etna eruption, Earth Planet. Sci. Lett., 245, 616-629.

CARbone, D. and F. GReCo (2007): Review of microgravity observations at Mt. Etna: a powerful tool to monitor and study active volcanoes, Pure Appl. Geophys., 164, $1-22$.

DAUBECHIES, I. (1992): Ten Lectures on Wavelets, CBMSNSF 61 Series in Applied Mathematics (SIAM, Philadelphia).

DAvis, P.M. (1981): Gravity and tilt earth tides measured on an active volcano, Mt Etna, Sicily, J. Volcanol. Geotherm. Res., 11, 213-223.

De Meyer, F., B. Ducarme and A. Elwahabi (1995): Continuous gravity observations at Mt. Etna (Sicily), in IUGG XXI General Assembly, July 2-14, Boulder, Colorado.

FerruCCI, F. and D. PATANE (1993): Seismic activity accompanying the outbreak of the 1991-1993 eruption of Mt. Etna, J. Volcanol. Geotherm. Res., 57, 125-135.

Imanishi, Y., T. Sato, T. Higashi, W. Sun and S. OKubo (2004): A network of superconducting gravimeters detects submicrogal coseismic gravity changes, Science, 306.

HindERER, J. and D. CRossley (2000): Time variations and inferences on the Earth's structure and dynamics, Surv. Geophys., 21, 1-45.

Nawa, K., N. Suda, Y. Fukao, T. Sato, Y. Aoyama and K. SHIBUYA (1998): Incessant excitation of the Earth's free oscillations, Earth Planets Space, 50, 3-8.

Patané, D., O. Cocina, S. Falsaperla, E. Privitera and S. SPAMPANATO (2004): Mt. Etna volcano: a seismological framework, in Etna Volcano Laboratory, edited by A. Bonaccorso, S. Calvari, M. Coltelli, C. Del Negro and S. Falsaperla, Am. Geophys. Un. (Geophysical Monograph series), 147-165.

RICHTER, C.F. (1958): Elementary Seismology (Freeman and Company San Francisco), pp. 768.

ToRGE, W. (1989): Gravimetry (Walter de Gruyter, BerlinNew York).

Wenzel, H.G. (1996): The nanogal software: Earth tide data processing package ETERNA 3.30, Bull. Inf. Marees Terrestres, 124, 9425-9439. 